\title{
Decomposition and Reconstruction of Signal in High-Speed Processing Method of Real-Time Spectral Analysis
}

\author{
Hideto Nakatsuji Member (Osaka Prefecture University, nakatsuji@sig.cs.osakafu-u.ac.jp) \\ Sigeru Omatu Member (Osaka Prefecture University, omatu@cs.osakafu-u.ac.jp)
}

Keywords: decomposition and reconstruction, time-frequency domain, integral wavelet transform

In recent years, the wavelet transform on the basis of multiresolution analysis has been concidered as a concrete algorithm of an integral wavelet transform which performs a spectral analysis in time-frequency domain. On the other hand, authors proposed a new analyzing method to obtain the spectrums by using the inner products of a signal and the cutting out waves which consist of sin and cosine wave. In the proposed method, the inner products are updated by using a new input data only and the spectrums are obtained. The new method proposes analysis approach 1 (AA1) which is a fundamental analysis method, and analysis approach 2(AA2) which is an analysis method that achieves high-speed processing. Decomposition and reconstruction of a signal based on AA1 was already proposed by the authors. This paper shows decomposition and reconstruction of a signal based on AA2.

Although the inner products become the decomposition waves in AA1, these do not become the decomposition waves in AA2. So in order to obtain the decomposition waves in $\mathrm{AA} 2$, a certain mathematical processing is needed. Here, sampling interval is $T_{s}$, and angular frequency of a cutting out wave is $\lambda$, and number of data in the cutting out wave is $N$. The cutting out wave is expressed as follow.

$$
\begin{array}{cl}
s(l)=\sin \left(\lambda l T_{s}\right) & c(l)=\cos \left(\lambda l T_{s}\right) \\
s(-l)=-s(l) & c(-l)=c(l) \\
l=1, \cdots, N &
\end{array}
$$

We express the inner product at time $k$ as $Y_{s}^{k}$ and $Y_{c}^{k} . Y_{s}^{k}$ is the inner product of which the cutting out wave is sine wave and $Y_{c}^{k}$ is the inner product of which the cuttin out wave is cosine wave. The mathematical processig to obtain the decomposition wave in AA2 is shown as follow.

Step1. Calculate inner the products $Y_{s}^{k}$ and $Y_{c}^{k}$ at time $k$.

Step2. Perform the following calculation by using the inner products $Y_{s}^{k}, Y_{c}^{k}$ and the cutting out wave $s(k), c(k)$.

$$
\begin{array}{ll}
Y_{s s}^{k}=Y_{s}^{k} s_{l}(k) & Y_{s c}^{k}=Y_{s}^{k} c_{l}(k) \\
Y_{c c}^{k}=Y_{c}^{k} c_{l}(k) & Y_{c s}^{k}=Y_{c}^{k} s_{l}(k)
\end{array}
$$

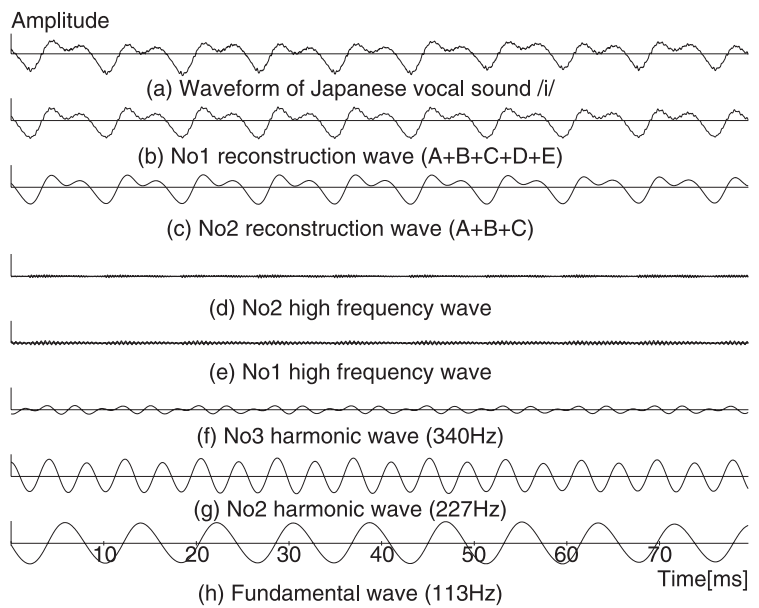

Fig. 1. The waveform of Japanese vocal sound /i/ and the waves which constitute vocal sound $/ \mathrm{i} /$ and the reconstruction waves

Step3. Caluculate next summation and difference.

$$
\begin{aligned}
& Y_{\text {cout }}^{k}=Y_{s s}^{k}+Y_{c c}^{k} \\
& Y_{\text {sout }}^{k}=Y_{s c}^{k}-Y_{c s}^{k}
\end{aligned}
$$

$Y_{\text {sout }}^{k}$ is the inner product of which the cutting out wave is sine wave and $Y_{\text {cout }}^{k}$ is the inner product of which the cutting out wave is cosine wave.

Step4. Replace $k$ with $k+1$ and repeat step1-step4.

By the Processsing, the $Y_{\text {cout }}^{k}$ and $Y_{\text {sout }}^{k}$ obtained in step3 is identical to the decomposition wave in AA1. Therfore, the decomposition and reconstruction of the signal in AA2 result in the decomposition and reconstruction of the signal in AA1. As an example of a numerical analysis, we show decomposition and reconstruction of Japanese vocal sound /i/. In Fig.1, No1 reconstrution wave is a wave pattern of the vocal sound /i/, but No2 reconstruction wave is not the wave pattern of it. 


\title{
リアルタイムスペクトル解析の高速処理法における 信号の分解と再構成
}

\author{
正員 中辻 秀人* 正員 大松 繁** \\ Decomposution and Reconstruction of Signal in High-Speed Processing Method of \\ Real-Time Spectral Analysis \\ Hideto Nakatsuji*, Member, Sigeru Omatu**, Member
}

\begin{abstract}
In recent years, the wavelet transform on the basis of multiresolution analysis has been considered as a concrete algorithm of an integral wavelet transform which performs a spectral analysis in time-frequency domain. On the other hand, authors have proposed a new analyzing method which updates the spectrum by using an input data only. The new method proposes analysis approach 1(AA1) which is a fundamental analysis method, and analysis approach 2(AA2) which is an analysis method that achieves high-speed processing. Decomposition and reconstruction of a signal based on AA1 was already proposed by the authors. This paper shows decomposition and reconstruction of a signal based on AA2. The decomposition wave in AA2 can not be obtained by the sama method as in the case of AA1 but by a mathematical processing. By the processing, the decomposition wave in AA2 is identical to the decomposition wave in AA1. Therefore, the decomposition and the reconstruction of the signal in AA2 result in the decomposition and the reconstruction of the signal in AA1. As an example of a numerical analysis, we show decomposition and reconstruction of Japanease vocal sound /i/.
\end{abstract}

キーワード : 分解と再構成, 時間周波数領域, 積分ウェーブレット変換

Keywords: decomposition and reconstruction, time-frequency domain, integral wavelet transform

\section{1. はじめに}

近年，信号の時間周波数領域での解析法としてウェーブ レット変換が注目されている。これに対して, 著者らは $T$ (自然数) 周期分の正弦波および余弦波（以下，切り出し波 と呼ぶ）と信号との内積を用いた時間周波数領域の解析法 を提案した ${ }^{(4)}$ 。以下では $T$ を周期数と呼ぶ。切り出し波の 長さは矩形空を有する空フーリエ変換の空の幅であり, こ れが一定になるように周期数 $T$ を変化させるとフーリエ解 析となる。周期数 $T$ を一定にすると切り出し波の長さ（空 の幅）は周波数に反比例して変化する。すなわち，周波数が 高くなると切り出し波の長さは短くなり, 低くなると長く なる。これはウェーブレットのスケールが周波数に応じて

\footnotetext{
$*$ 大阪府立大学工学部

599-8531 堺市中区学園町 1-1

Department of Engineering, Osaka Prefecture University

1-1 Gakuen, Nakaku, Sakai City, Osaka 599-8531

** 大阪府立大学大学院工学研究科

599-8531 堺市中区学園町 1-1

Graduate School of Engineering, Osaka Prefecture University 1-1 Gakuen, Nakaku, Sakai City, Osaka 599-8531
}

変化する機能と同じである。このように提案解析法はフー リエ解析として，また積分ウェーブレット変換として用い ることができる。提案解析法は音声信号のように短い時間 間隔でデータが次々と入ってくるような信号をリアルタイ ムに処理することを考慮して考案されたものであり，よっ て新しく入力されたデータのみを用いてスペクトル等を更 新する手法となっている。更新の手法として解析 1 と 演算 量を大幅に低減して高速処理を実現する解析 2 の二つの解 析法がある。時間周波数領域での解析において, ウェーブ レット変換では信号の分解, 再構成が示されており, 短時 間フーリ工変換では空が重なっているため, 再構成は一意 的に決まらないが，幾つか考察されている(1)。短時間フー リ工変換による解析と提案解析法による解析の違いは空の 幅が周波数に応じて変化することであり, 短時間フーリエ 変換の場合と同様に, 提案解析法においても信号の分解と 再構成の手法がある。解析 1 にもとづいた信号の分解と再 構成は，すでに著者らによって示された ${ }^{(5)}$ 。解析 1 では切 り出し波と信号との内積が分解波になることを示したが, 解析 2 においては，この内積は分解波にならない。そこで, 本論文では, この内積に数学的処理を施すことにより得ら 
れる波が解析 1 における分解波と同じになることを示し， もって解析 2 の信号の分解と再構成は解析 1 の信号の分解 と再構成の問題に帰着することを示す。解析 2 を用いた数 值解析例として, 日本語音声 $/ \mathrm{i} /$ が基本波, 高調波および高 周波数の波で表されることを示す。また，これらの波を加 えた再構成波で wave ファイルを作成し，これを再生して 聞くことにより，音声/i/を特徴付けているパターンを明ら かにすることで, 提案解析法による信号の分解と再構成の 有用性を示す。

\section{2. 解析 2 の概要}

サンプリング間隔を $T_{s}$, 切り出し波の設定周波数を $f_{j}$ (角周波数 $\lambda_{j}=2 \pi f_{j}$ ) とする。ここで， $j(=1,2, \cdots, n$ ) は切り出し波の番号で, $n$ は切り出し波の数である。切り 出し波の長さ $q_{j}\left(=T / f_{j}\right)$ の中に含まれるデー夕数を $N_{j}$ とすると, 切り出し波は，つぎのように表されるとともに， 以下に示す関係が成立する。

$$
\begin{array}{ll}
s_{j}(l)=\sin \left(\lambda_{j} l T_{s}\right) & c_{j}(l)=\cos \left(\lambda_{j} l T_{s}\right) \\
s_{j}(-l)=-s_{j}(l) & c_{j}(-l)=c_{j}(l) \\
s_{j}\left(k+N_{j}\right)=s_{j}(k) & c_{j}\left(k+N_{j}\right)=c_{j}(k) \cdots
\end{array}
$$

$k$; natural number $\quad l=1, \cdots, N_{j}$

提案解析法は切り出し波と信号との内積を計算して設定周 波数 $f_{j}$ に近い信号成分を検出するものでである。解析 2 は, 切り出し波として正弦波と余弦波を同時に用いて，時間の 推移ともに切り出し波の位相も変化させつつ, 内積の計算 を新しく入力された 1 個のデータのみを用いた更新により 実施することで，演算量の低減を図るものである。切り出 し波が余弦波の場合も同様に展開できるので，ここでは正 弦波の場合について示す。時刻 $k T_{s}$ における信号を $x(k)$ と し，過去に遡った信号を用いて，内積をつぎのように表す。

$$
Y_{s}^{k}(j)=\frac{2}{N_{j}} \sum_{l=1}^{N_{j}} x(k-l) s_{j}(l-k)
$$

時刻 $(k+1) T_{s}$ の時の内積は，つぎのように表される。

$$
\begin{aligned}
Y_{s}^{k+1}(j)= & \frac{2}{N_{j}} \sum_{l=1}^{N_{j}} x(k+1-l) s_{j}(l-k-1) \\
= & \frac{2}{N_{j}} x(k) s_{j}(-k)+Y_{s}^{k}(j) \\
& -\frac{2}{N_{j}} x\left(k-N_{j}\right) s_{j}\left(N_{j}-k\right) \cdots \ldots .
\end{aligned}
$$

(3) 式の右辺第 2 項と第 3 項は既に計算されたものであり, (3) 式の計算で必要な計算は第 1 項の掛け算 1 回だけとな る。すなわち, 時刻 $(k+1) T_{s}$ での内積は時刻 $k T_{s}$ での内積 から (3) 式の右辺第 3 項を引いて第 1 項を加えるという更新 演算によって行うことができる。(3) 式において $N_{j}-k=0$ の場合，(3) 式の右辺第 3 項の $s_{j}\left(N_{j}-k\right)$ は $s_{j}(0)$ となる が, (1) 式より, これは $s_{j}\left(N_{j}\right)$ となる。切り出し波が余弦
波の場合も，同様に更新によって内積 $Y_{c}^{k}(j)$ を計算する。 このようにして求めた $Y_{s}^{k}(j)$ と $Y_{c}^{k}(j)$ を用いて

$$
Y_{\text {out }}^{k}(j)=\sqrt{Y_{s}^{k}(j)^{2}+Y_{c}^{k}(j)^{2}} \ldots \ldots \ldots \ldots \ldots
$$

を計算する。 $Y_{o u t}^{k}(j)$ は, 特定の周波数 $f_{j}$ に近い周波数を 有する信号を検出するユニットであり, 以下では, このユ ニットを聴覚細胞と呼ぶこととする。上述より解析 2 では 内積 $Y_{s}^{k}(j), Y_{c}^{k}(j)$ の式の数は各 1 個であるが, 解析 1 で は切り出し波が繰り返す周期数の中のデータ数だけ式の数 がある。低い設定周波数の聴覚細胞では 1 周期の中のデー 夕数が多いため，1 周期で繰り返すようにしながら設定周波 数を概ね一定の比率で増加させることができる。たとえば サンプリング周波数が $44.1 \mathrm{kHz}$, 周期数 $T\left(=2^{4}\right)$ で設定周 波数を約 $1.5 \%$ で増加させる場合, 設定周波数が $10 \mathrm{~Hz}$ の聴 覚細胞では 1 周期 (0.1 秒) の中のデー夕数は 4,410 個であ り,つぎの聴覚細胞の設定周波数を約 $1.5 \%$ 増加させるた め, 1 周期の中のデー夕数を 4,345 個とすると, $10.1496 \mathrm{~Hz}$ となり, 増加率は 1.496 \%となって, 約 $1.5 \%$ の増加と見做 せる。解析 2 では式の数は 1 個であるから, この場合, 演 算量はそれぞれ $1 / 4,410$ 倍，1/4,345 倍となる。設定周波 数が高くなると 1 周期の中のデー夕数が小さくなって, 約 $1.5 \%$ の増加率と見做せなくなる。たとえば，設定周波数が $900 \mathrm{~Hz}$ では 1 周期の中のデー夕数は 49 個であり, 1 個減 らして 48 個にすると設定周波数は $918.75 \mathrm{~Hz}$ となって, 増 加率は 2.08 \%になる。これでは約 $1.5 \%$ とは見做せない。 よって 1 周期で繰り返すのではなく複数周期で繰り返すよ うにする必要がある。周期数 $T\left(=2^{4}\right)$ であるので, 1 周期 の中のデー夕数が小さくなって約 $1.5 \%$ の増加が困難になっ たら 2 周期で繰り返すようにし, それでも困難になったら 4 周期で, さらに 8 周期, 最大で $T$ 周期で繰り返すように する。解析 1 ではこの繰り返す周期数の中のデータ数だけ 式の数があるから, 解析 2 は解析 1 に比べて各聴覚細胞で の演算量が $1 /$ (式の数) となる。

切り出し波の数 $n$ は聴覚細胞の数であり, 解析 2 では内 積の更新に必要な掛け算回数は $2 n$ 回である。また各聴覚 細胞および内積 $Y_{s}^{k}(j), Y_{c}^{k}(j)$ の計算は独立していること から並列処理が可能であり, 並列処理を導入した場合, 更 新に必要な掛け算回数は 1 回になる。

\section{3. 聴覚細胞の信号検出範囲}

切出し波の長さ $q_{j}\left(=T / f_{j}\right)$ の中には周波数 $f_{j}$ の波が $T$ 周期分存在する。 $q_{j}$ の中で $T+1$ 周期分となる信号の周 波数は $f_{j}+f_{j} / T$ であり, この聴覚細胞はこの信号を検出 できない。同様に周波数 $f_{j}-f_{j} / T$ の信号も検出できない。 この聴覚細胞の信号検出幅を $B$ とすると, $B=2 f_{j} / T$ と なる。これは周波数幅 $B$ と切出し波の長さ $T / f_{j}$ で作られ る面積が一定の $2\left(=B T / f_{j}\right)$ であることを示している。 $T$ を一定にすると $B / f_{j}$ も一定になる。すなわち設定周波 数が高くなると $B$ も大きくなるのである。 


\section{4. 信号の分解}

$\langle\mathbf{4} \cdot \mathbf{1}\rangle$ 解析 $\mathbf{2}$ における内積と連続系での表現 信号 の角周波数を $\omega_{i}$, 振幅を $A_{i}$, 位相を $\phi_{i}$ とする。ここで, $i(=1,2, \cdots, m)$ は信号成分の番号で, $m$ は信号成分の数 である。時刻 $k T_{s}$ から遡った過去の信号を，つぎのように 表す。

$$
x_{i}(k-l)=A_{i} \sin \left(\omega_{i}(k-l) T_{s}+\phi_{i}\right) .
$$

(1) 式の 2 番目の関係を用いて, 時刻 $k T_{s}$ での内積を再度 書き表す。

$$
\begin{aligned}
& Y_{s}^{k}(i, j)=-\frac{2}{N_{j}} \sum_{l=1}^{N_{j}} x_{i}(k-l) s_{j}(k-l) \\
& Y_{c}^{k}(i, j)=\frac{2}{N_{j}} \sum_{l=1}^{N_{j}} x_{i}(k-l) c_{j}(k-l) \cdots
\end{aligned}
$$

はじめに，(6) 式の第 1 式について展開する。(1) 式の $s_{j}(l)$ と（5)式を用いると，つぎのように表される。

$Y_{s}^{k}(i, j)$

$$
\begin{aligned}
= & -\frac{2}{N_{j}} A_{i} \sum_{l=1}^{N_{j}} \sin \left(\omega_{i}(k-l) T_{s}+\phi_{i}\right) \sin \left(\lambda_{j}(k-l) T_{s}\right) \\
= & -\frac{2}{N_{j}} A_{i}\left\{\cos \left(\phi_{i}\right) \sum_{j=1}^{N_{j}} \sin \left(\omega_{i}(k-l) T_{s}\right) \sin \left(\lambda_{j}(k-l) T_{s}\right)\right. \\
& \left.+\sin \left(\phi_{i}\right) \sum_{l=1}^{N_{j}} \cos \left(\omega_{i}(k-l) T_{s}\right) \sin \left(\lambda_{j}(k-l) T_{s}\right)\right\}
\end{aligned}
$$

ここで, $t=k T_{s}, \tau=l T_{s}$ と拉き, $N_{j}=q_{j} / T_{s}, q_{j}=T / f_{j}$ の関係を用いると，つぎのように表される。

$Y_{s}^{k}(i, j)$

$$
\begin{aligned}
= & -\frac{2 f_{j}}{T} A_{i} \cos \left(\phi_{i}\right) \sum_{l=1}^{N_{j}} \sin \left(\omega_{i}(t-\tau)\right) \sin \left(\lambda_{j}(t-\tau)\right) T_{s} \\
& -\frac{2 f_{j}}{T} A_{i} \sin \left(\phi_{i}\right) \sum_{l=1}^{N_{j}} \cos \left(\omega_{i}(t-\tau)\right) \sin \left(\lambda_{j}(t-\tau)\right) T_{s}
\end{aligned}
$$

ここで，T信限小にすると

$$
\begin{aligned}
& \hat{Y}_{s}(i, j, t) \\
& =-\frac{2 f_{j}}{T} A_{i} \cos \left(\phi_{i}\right) \int_{0}^{q_{j}} \sin \left(\omega_{i}(t-\tau)\right) \sin \left(\lambda_{j}(t-\tau)\right) d \tau \\
& \quad-\frac{2 f_{j}}{T} A_{i} \sin \left(\phi_{i}\right) \int_{0}^{q_{j}} \cos \left(\omega_{i}(t-\tau)\right) \sin \left(\lambda_{j}(t-\tau)\right) d \tau
\end{aligned}
$$

と表される。同様に (6) 式の第 2 式は，つぎのように表さ れる。

$$
\begin{aligned}
& \hat{Y}_{c}(i, j, t) \\
& =\frac{2 f_{j}}{T} A_{i} \cos \left(\phi_{i}\right) \int_{0}^{q_{j}} \sin \left(\omega_{i}(t-\tau)\right) \cos \left(\lambda_{j}(t-\tau)\right) d \tau \\
& \quad+\frac{2 f_{j}}{T} A_{i} \sin \left(\phi_{i}\right) \int_{0}^{q_{j}} \cos \left(\omega_{i}(t-\tau)\right) \cos \left(\lambda_{j}(t-\tau)\right) d \tau
\end{aligned}
$$

内積を表す (6) 式と積分で表された (9) 式，(10) 式は本 質的に同じである。

$\langle\mathbf{4} \cdot \mathbf{2}\rangle$ 低周波数と高周波数の波への分離 $\quad(9)$ 式は, つぎのように表される。

$$
\begin{aligned}
& \hat{Y}_{s}(i, j, t) \\
&=-\frac{2 f_{j}}{T} A_{i} \cos \left(\phi_{i}\right) \int_{0}^{q_{j}}\left(\frac{1}{2} \cos \left(\left(\omega_{i}-\lambda_{j}\right)(t-\tau)\right)\right. \\
&\left.-\frac{1}{2} \cos \left(\left(\omega_{i}+\lambda_{j}\right)(t-\tau)\right)\right) d \tau \\
& \quad-\frac{2 f_{j}}{T} A_{i} \sin \left(\phi_{i}\right) \int_{0}^{q_{j}}\left(-\frac{1}{2} \sin \left(\left(\omega_{i}-\lambda_{j}\right)(t-\tau)\right)\right. \\
&+\left.\frac{1}{2} \sin \left(\left(\omega_{i}+\lambda_{j}\right)(t-\tau)\right)\right) d \tau \\
&=-\frac{f_{j}}{T} A_{i} \int_{0}^{q_{j}}\left(\cos \left(\phi_{i}\right) \cos \left(\left(\omega_{i}-\lambda_{j}\right)(t-\tau)\right)\right. \\
&\left.-\sin \left(\phi_{i}\right) \sin \left(\left(\omega_{i}-\lambda_{j}\right)(t-\tau)\right)\right) d \tau \\
&+\frac{f_{j}}{T} A_{i} \int_{0}^{q_{j}}\left(\cos \left(\phi_{i}\right) \cos \left(\left(\omega_{i}+\lambda_{j}\right)(t-\tau)\right)\right. \\
&\left.-\sin \left(\phi_{i}\right) \sin \left(\left(\omega_{i}+\lambda_{j}\right)(t-\tau)\right)\right) d \tau \\
&=-\frac{f_{j}}{T} A_{i} \int_{0}^{q_{j}} \cos \left(\left(\omega_{i}-\lambda_{j}\right)(t-\tau)+\phi_{i}\right) d \tau \\
&\left.+\frac{f_{j}}{T} A_{i} \int_{0}^{q_{j}} \cos \left(\left(\omega_{i}+\lambda_{j}\right)(t-\tau)+\phi_{i}\right)\right) d \tau \cdots(11) \\
&-\tau
\end{aligned}
$$

ここで, $\mu=t-\tau, \omega_{i j}^{-}=\omega_{i}-\lambda_{j}, \omega_{i j}^{+}=\omega_{i}+\lambda_{j}$, と おくと (11) 式は，つぎのように表される。 $\hat{Y}_{s}(i, j, t)=\frac{f_{j}}{T} A_{i} \int_{t}^{t-q_{j}} \cos \left(\omega_{i j}^{-} \mu+\phi_{i}\right) d \mu$

$$
\begin{aligned}
& -\frac{f_{j}}{T} A_{i} \int_{t}^{t-q_{j}} \cos \left(\omega_{i j}^{+} \mu+\phi_{i}\right) d \mu \\
= & \left.\frac{f_{j}}{T} A_{i} \frac{1}{\omega_{i j}^{-}} \sin \left(\omega_{i j}^{-} \mu+\phi_{i}\right)\right|_{t} ^{t-q_{j}} \\
& -\left.\frac{f_{j}}{T} A_{i} \frac{1}{\omega_{i j}^{+}} \sin \left(\omega_{i j}^{+} \mu+\phi_{i}\right)\right|_{t} ^{t-q_{j}} \\
= & \frac{f_{j}}{T} A_{i} \frac{1}{\omega_{i j}^{-}}\left(\sin \left(\omega_{i j}^{-} t+\phi_{i}-\omega_{i j}^{-} q_{j}\right)-\sin \left(\omega_{i j}^{-} t+\phi_{i}\right)\right) \\
& -\frac{f_{j}}{T} A_{i} \frac{1}{\omega_{i j}^{+}}\left(\sin \left(\omega_{i j}^{+} t+\phi_{i}-\omega_{i j}^{+} q\right)-\sin \left(\omega_{i j}^{+} t+\phi_{i}\right)\right) \\
= & -\frac{2 f_{j}}{T} A_{i} \frac{1}{\omega_{i j}^{-}} \cos \left(\omega_{i j}^{-} t+\phi_{i}-\frac{\omega_{i j}^{-}}{2} q_{j}\right) \sin \left(\frac{\omega_{i j}^{-}}{2} q_{j}\right) \\
& +\frac{2 f_{j}}{T} A_{i} \frac{1}{\omega_{i j}^{+}} \cos \left(\omega_{i j}^{+} t+\phi_{i}-\frac{\omega_{i j}^{+}}{2} q_{j}\right) \sin \left(\frac{\omega_{i j}^{+}}{2} q_{j}\right)
\end{aligned}
$$




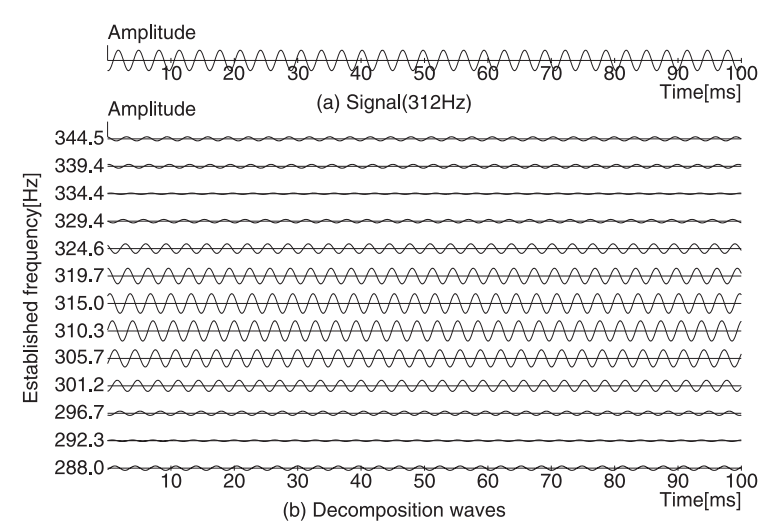

Fig. 1. Decomposition waves by AA1

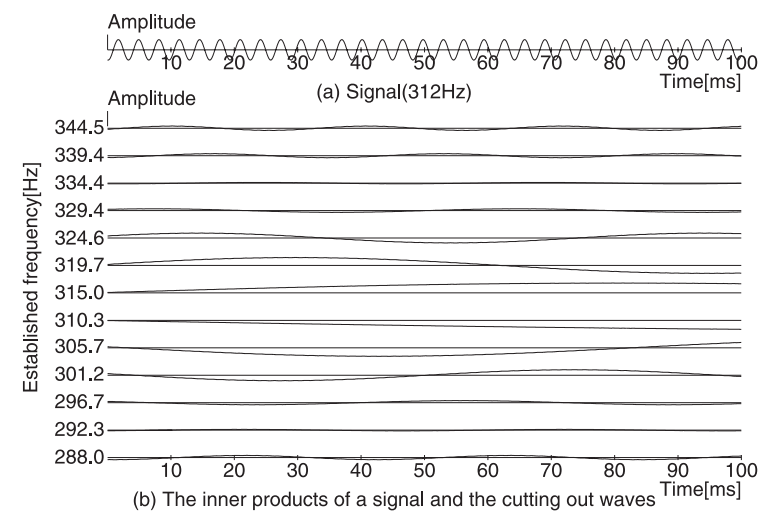

Fig. 2. The waves expressed with the inner product of AA2

(10)式も同様の展開で，つぎのように表される。

$$
\begin{gathered}
\hat{Y}_{c}(i, j, t)=\frac{2 f_{j}}{T} A_{i} \frac{1}{\omega_{i j}^{-}} \sin \left(\omega_{i j}^{-} t+\phi_{i}-\frac{\omega_{i j}^{-}}{2} q_{j}\right) \sin \left(\frac{\omega_{i j}^{-}}{2} q_{j}\right) \\
+\frac{2 f_{j}}{T} A_{i} \frac{1}{\omega_{i j}^{+}} \sin \left(\omega_{i j}^{+} t+\phi_{i}-\frac{\omega_{i j}^{+}}{2} q_{j}\right) \sin \left(\frac{\omega_{i j}^{+}}{2} q_{j}\right)
\end{gathered}
$$

(12) 式と (13) 式の右辺の第 1 項は信号の周波数と聴覚細 胞の設定周波数の周波数差 $\omega_{i j}^{-}$の低周波数の波であり, 第 2 項はこれらの周波数が加え合わされた高周波数 $\omega_{i j}^{+}$の波 を表している。解析 2 で計算される内積は，このように高 周波数の波と低周波数の波が加え合わされた波となる。文 献 (5) より, 解析 1 では内積が分解波となった。信号の周 波数を $312 \mathrm{~Hz}$ とし, サンプリング周波数 $44.1 \mathrm{kHz}$ で, 聴 覚細胞の設定周波数が $288 \mathrm{~Hz}$ から約 $1.5 \%$ づつ増加させて 約 $345 \mathrm{~Hz}$ までの 13 個の聴覚細胞を用いたときの，解析 1 における分解波を Fig.1 に示す。Fig.1において, $312 \mathrm{~Hz}$ に 最も近い $310.3 \mathrm{~Hz}$ の設定周波数の聴覚細胞で最も大きな分 解波が現れている。また, どの聴覚細胞の分解波も $312 \mathrm{~Hz}$ の波になっている。解析 2 で計算した内積の波を Fig. 2 に 示す。Fig.2の波は, 各聴覚細胞ごとに異なった周波数の波 になっており，分解波になっていない。

$\langle\mathbf{4} \cdot \mathbf{3}\rangle$ 解析 $\mathbf{2}$ における分解波の生成処理 $\langle 4 \cdot 2\rangle$ 節に おいて, Fig.2 は解析 2 における内積であり, これは (12)
式，(13) 式で示されたように信号の周波数と聴覚細胞の設 定周波数との周波数差である低周波数の波と和である高周波 数の波で構成されていることを示した。ここでは，この内積 から分解波を得ることを示す。(12) 式, (13) 式に切り出し 波 $-s_{j}(t)$ と $c_{j}(t)$ を掛け合わせた $\tilde{Y}_{s s}(i, j, t), \tilde{Y}_{c c}(i, j, t)$, $\tilde{Y}_{s c}(i, j, t)$ および $\tilde{Y}_{c s}(i, j, t)$ を考える。

$\tilde{Y}_{s s}(i, j, t)=-\hat{Y}_{s}(i, j, t) s_{j}(t) \quad \tilde{Y}_{s c}(i, j, t)=\hat{Y}_{s}(i, j, t) c_{j}(t)$ $\tilde{Y}_{c s}(i, j, t)=-\hat{Y}_{c}(i, j, t) s_{j}(t) \quad \tilde{Y}_{c c}(i, j, t)=\hat{Y}_{c}(i, j, t) c_{j}(t)$

ここで, $s_{j}(t)=\sin \left(\lambda_{j} t\right)$ および $c_{j}(t)=\cos \left(\lambda_{j} t\right)$ であ る。つぎに $\tilde{Y}_{s s}(i, j, t)$ と $\tilde{Y}_{c c}(i, j, t)$ の和 $Y_{o u t}^{+}(i, j, t)$ および $\tilde{Y}_{s c}(i, j, t)$ と $\tilde{Y}_{c s}(i, j, t)$ の差 $Y_{o u t}^{-}(i, j, t)$ について考える。

$$
\begin{aligned}
& Y_{\text {out }}^{+}(i, j, t)=\tilde{Y}_{s s}(i, j, t)+\tilde{Y}_{c c}(i, j, t) \\
& =\frac{2 f_{j}}{T} A_{i} \frac{1}{\omega_{i j}^{-}} \sin \left(\frac{\omega_{i j}^{-}}{2} q_{j}\right)\left(\cos \left(\omega_{i j}^{-} t+\phi_{i}-\frac{\omega_{i j}^{-}}{2} q_{j}\right) \sin \left(\lambda_{j} t\right)\right. \\
& \left.\quad+\sin \left(\omega_{i j}^{-} t+\phi_{i}-\frac{\omega_{i j}^{-}}{2} q_{j}\right) \cos \left(\lambda_{j} t\right)\right) \\
& \quad+\frac{2 f_{j}}{T} A_{i} \frac{1}{\omega_{i j}^{+}} \sin \left(\frac{\omega_{i j}^{+}}{2} q_{j}\right)\left(-\cos \left(\omega_{i j}^{+} t+\phi_{i}\right.\right. \\
& \left.\left.\quad-\frac{\omega_{i j}^{+}}{2} q_{j}\right) \sin \left(\lambda_{j} t\right)+\sin \left(\omega_{j}^{+} t+\phi_{i}-\frac{\omega_{i j}^{+}}{2} q_{j}\right) \cos \left(\lambda_{j} t\right)\right) \\
& Y_{\text {out }}^{-}(i, j, t)=\tilde{Y}_{s c}(i, j, t)-\tilde{Y}_{c s}(i, j, t) \\
& =-\frac{2 f_{j}}{T} A_{i} \frac{1}{\omega_{i j}^{-}} \sin \left(\frac{\omega_{i j}^{-}}{2} q_{j}\right)\left(\cos \left(\omega_{i j}^{-} t+\phi_{i}-\frac{\omega_{i j}^{-}}{2} q_{j}\right) \cos \left(\lambda_{j} t\right)\right. \\
& \left.\quad-\sin \left(\omega_{i j}^{-} t+\phi_{i}-\frac{\omega_{i j}^{-}}{2} q_{j}\right) \sin \left(\lambda_{j} t\right)\right) \\
& \quad+\frac{2 f_{j}}{T} A_{i} \frac{1}{\omega_{i j}^{+}} \sin \left(\frac{\omega_{i j}^{+}}{2} q_{j}\right)\left(\cos \left(\omega_{i j}^{+} t+\phi_{i}-\frac{\omega_{i j}^{+}}{2} q_{j}\right) \cos \left(\lambda_{j} t\right)\right. \\
& \left.\quad+\sin \left(\omega_{i j}^{+} t+\phi_{i}-\frac{\omega_{i j}^{+}}{2} q_{j}\right) \sin \left(\lambda_{j} t\right)\right) \ldots \ldots(15)
\end{aligned}
$$

ここで, $\omega_{i j}^{-}=\omega_{i}-\lambda_{j}, \omega_{i j}^{+}=\omega_{i}+\lambda_{j}$ であることを考慮 すると $Y_{\text {out }}^{+}(i, j, t)$ は，つぎのように表される。

$$
\begin{aligned}
Y_{\text {out }}^{+} & (i, j, t) \\
= & \frac{2 f_{j}}{T} A_{i} \frac{1}{\omega_{i j}^{-}} \sin \left(\frac{\omega_{i j}^{-}}{2} q_{j}\right) \sin \left(\left(\omega_{i j}^{-}+\lambda_{j}\right) t+\phi_{i}-\frac{\omega_{i j}^{-}}{2} q_{j}\right) \\
& +\frac{2 f_{j}}{T} A_{i} \frac{1}{\omega_{i j}^{+}} \sin \left(\frac{\omega_{i j}^{+}}{2} q_{j}\right) \sin \left(\left(\omega_{i j}^{+}-\lambda_{j}\right) t+\phi_{i}-\frac{\omega_{i j}^{+}}{2} q_{j}\right) \\
= & \frac{2 f_{j}}{T} A_{i} \frac{1}{\omega_{i j}^{-}} \sin \left(\frac{\omega_{i j}^{-}}{2} q_{j}\right) \sin \left(\omega_{i} t+\phi_{i}-\frac{\omega_{i j}^{-}}{2} q_{j}\right) \\
& +\frac{2 f_{j}}{T} A_{i} \frac{1}{\omega_{i j}^{+}} \sin \left(\frac{\omega_{i j}^{+}}{2} q_{j}\right) \sin \left(\omega_{i} t+\phi_{i}-\frac{\omega_{i j}^{+}}{2} q_{j}\right) \\
= & \frac{2 f_{j}}{T} A_{i}\left\{\frac { 1 } { \omega _ { i j } ^ { - } } \operatorname { s i n } ( \frac { \omega _ { i j } ^ { - } } { 2 } q _ { j } ) \left(\cos \left(\frac{\omega_{i j}^{-}}{2} q_{j}\right) \sin \left(\omega_{i} t+\phi_{i}\right)\right.\right. \\
& \left.-\sin \left(\frac{\omega_{i j}^{-}}{2} q_{j}\right) \cos \left(\omega_{i} t+\phi_{i}\right)\right)
\end{aligned}
$$




$$
\begin{aligned}
& +\frac{1}{\omega_{i j}^{+}} \sin \left(\frac{\omega_{i j}^{+}}{2} q_{j}\right)\left(\cos \left(\frac{\omega_{i j}^{+}}{2} q_{j}\right) \sin \left(\omega_{i} t+\phi_{i}\right)\right. \\
& \left.\left.-\sin \left(\frac{\omega_{i j}^{+}}{2} q_{j}\right) \cos \left(\omega_{i} t+\phi_{i}\right)\right)\right\} \\
= & \frac{2 f_{j}}{T} A_{i}\left\{\left(\frac{1}{\omega_{i j}^{-}} \sin \left(\frac{\omega_{i j}^{-}}{2} q_{j}\right) \cos \left(\frac{\omega_{i j}^{-}}{2} q_{j}\right)\right.\right. \\
& \left.+\frac{1}{\omega_{i j}^{+}} \sin \left(\frac{\omega_{i j}^{+}}{2} q_{j}\right) \cos \left(\frac{\omega_{i j}^{+}}{2} q_{j}\right)\right) \sin \left(\omega_{i} t+\phi_{i}\right) \\
& \left.-\left(\frac{1}{\omega_{i j}^{+}} \sin ^{2}\left(\frac{\omega_{i j}^{+}}{2} q_{j}\right)+\frac{1}{\omega_{i j}^{-}} \sin ^{2}\left(\frac{\omega_{i j}^{-}}{2} q_{j}\right)\right) \cos \left(\omega_{i} t+\phi_{i}\right)\right\}
\end{aligned}
$$

同様に， $Y_{\text {out }}^{-}(i, j, t)$ は，つぎのように表される。

$$
\begin{aligned}
& Y_{\text {out }}^{-}(i, j, t) \\
& =\frac{2 f_{j}}{T} A_{i}\left\{-\left(\frac{1}{\omega_{i j}^{-}} \sin \left(\frac{\omega_{i j}^{-}}{2} q_{j}\right) \cos \left(\frac{\omega_{i j}^{-}}{2} q_{j}\right)\right.\right. \\
& \left.\quad-\frac{1}{\omega_{i j}^{+}} \sin \left(\frac{\omega_{i j}^{+}}{2} q_{j}\right) \cos \left(\frac{\omega_{i j}^{+}}{2} q_{j}\right)\right) \cos \left(\omega_{i} t+\phi_{i}\right) \\
& \left.\quad-\left(\frac{1}{\omega_{i j}^{-}} \sin ^{2}\left(\frac{\omega_{i j}^{-}}{2} q_{j}\right)-\frac{1}{\omega_{i j}^{+}} \sin ^{2}\left(\frac{\omega_{i j}^{+}}{2} q_{j}\right)\right) \sin \left(\omega_{i} t+\phi_{i}\right)\right\}
\end{aligned}
$$

ここで

$$
\begin{aligned}
G_{+}(i, j)= & \frac{2 f_{j}}{T}\left\{\frac{1}{\omega_{i j}^{-}} \sin \left(\frac{\omega_{i j}^{-}}{2} q_{j}\right) \cos \left(\frac{\omega_{i j}^{-}}{2} q_{j}\right)\right. \\
& \left.+\frac{1}{\omega_{i j}^{+}} \sin \left(\frac{\omega_{i j}^{+}}{2} q_{j}\right) \cos \left(\frac{\omega_{i j}^{+}}{2} q_{j}\right)\right\} \\
H_{+}(i, j)= & \frac{2 f_{j}}{T}\left(\frac{1}{\omega_{i j}^{+}} \sin ^{2}\left(\frac{\omega_{i j}^{+}}{2} q_{j}\right)+\frac{1}{\omega_{i j}^{-}} \sin ^{2}\left(\frac{\omega_{i j}^{-}}{2} q_{j}\right)\right) \\
G_{-}(i, j)= & \frac{2 f_{j}}{T}\left\{\frac{1}{\omega_{i j}^{-}} \sin \left(\frac{\omega_{i j}^{-}}{2} q\right) \cos \left(\frac{\omega_{i j}^{-}}{2} q_{j}\right)\right. \\
& \left.-\frac{1}{\omega_{i j}^{+}} \sin \left(\frac{\omega_{i j}^{+}}{2} q_{j}\right) \cos \left(\frac{\omega_{i j}^{+}}{2} q_{j}\right)\right\} \\
H_{-}(i, j)= & \frac{2 f_{j}}{T}\left(\frac{1}{\omega_{i j}^{+}} \sin ^{2}\left(\frac{\omega_{i j}^{+}}{2} q_{j}\right)-\frac{1}{\omega_{i j}^{-}} \sin ^{2}\left(\frac{\omega_{i j}^{-}}{2} q_{j}\right)\right)
\end{aligned}
$$

とおくと (16) 式，(17) 式は，つぎのように表される。

$Y_{\text {out }}^{+}(i, j, t)=$

$A_{i}\left(G_{+}(i, j) \sin \left(\omega_{i} t+\phi_{i}\right)-H_{+}(i, j) \cos \left(\omega_{i} t+\phi_{i}\right)\right)$

$Y_{\text {out }}^{-}(i, j, t)=$

$A_{i}\left(-G_{-}(i, j) \cos \left(\omega_{i} t+\phi_{i}\right)+H_{-}(i, j) \sin \left(\omega_{i} t+\phi_{i}\right)\right)$

さらに

$$
\begin{aligned}
& \Gamma_{+}(i, j)=\sqrt{G_{+}^{2}(i, j)+H_{+}^{2}(i, j)} \\
& \Psi_{+}(i, j)=\tan ^{-1}\left(-H_{+}(i, j) / G_{+}(i, j)\right)
\end{aligned}
$$

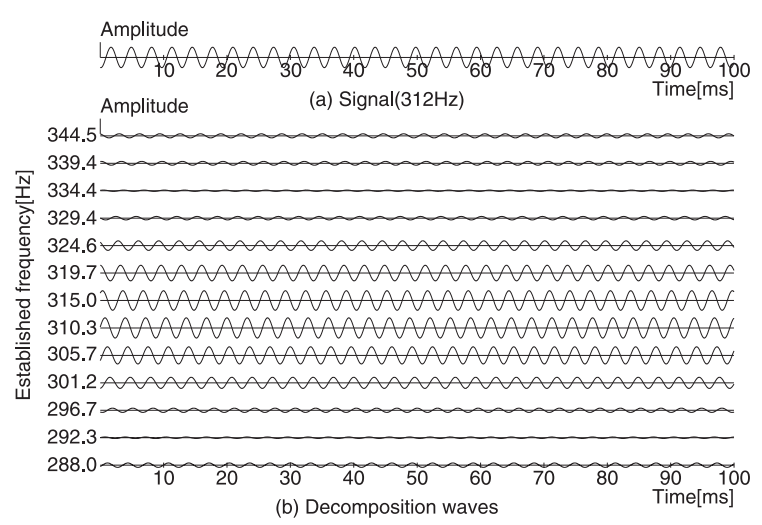

Fig. 3. Decomposition waves by AA2

$$
\begin{aligned}
& \Gamma_{-}(i, j)=\sqrt{G_{-}^{2}(i, j)+H_{-}^{2}(i, j)} \\
& \Psi_{-}(i, j)=\tan ^{-1}\left(G_{-}(i, j) / H_{-}(i, j)\right)
\end{aligned}
$$

とおくと (19) 式は，つぎのように表される。

$$
\begin{array}{r}
Y_{\text {out }}^{+}(i, j, t)=A_{i} \Gamma_{+}(i, j)\left(\sin \left(\omega_{i} t+\phi_{i}+\Psi_{+}(i, j)\right)\right. \\
Y_{\text {out }}^{-}(i, j, t)=A_{i} \Gamma_{-}(i, j)\left(\sin \left(\omega_{i} t+\phi_{i}+\Psi_{-}(i, j)\right)\right. \\
\ldots \ldots \ldots \ldots \ldots \ldots
\end{array}
$$

(21) 式は周波数が信号の周波数 $\omega_{i}$ で，元の信号に対し て，振幅がそれぞれ $\Gamma_{+}(i, j)$ 倍および $\Gamma_{-}(i, j)$ 倍で，新 たに位相 $\Psi_{+}(i, j)$ および $\Psi_{-}(i, j)$ が生じている。 $(21)$ 式 の $Y_{\text {out }}^{+}(i, j, t)$ を Fig.3 に示す。Fig.3 は連続系において解 析的に得られたが, 解析 2 の内積である (6) 式から同様の 処理によって, Fig.3 と本質的に同じものが得られる。この 手順は，つぎのように表される。

step1 2 章で示した解析 2 の手法を用いて (6) 式で示した 時刻 $k T_{s}$ のときの内積 $Y_{s}^{k}(i, j), Y_{c}^{k}(i, j)$ を計算する。 step2 内積 $Y_{s}^{k}(i, j), Y_{c}^{k}(i, j)$ に, (1) 式で表される切り

出し波 $-s_{j}(k), c_{j}(k)$ を掛けて

$$
\begin{aligned}
& Y_{s s}^{k}(i, j)=-Y_{s}^{k}(i, j) s_{j}(k) \quad Y_{s c}^{k}(i, j)=Y_{s}^{k}(i, j) c_{j}(k) \\
& Y_{c c}^{k}(i, j)=Y_{c}^{k}(i, j) c_{j}(k) \quad Y_{c s}^{k}(i, j)=-Y_{c}^{k}(i, j) s_{j}(k)
\end{aligned}
$$

を求める。 step3 $Y_{s s}^{k}(i, j), Y_{s c}^{k}(i, j), Y_{c c}^{k}(i, j)$ および $Y_{c s}^{k}(i, j)$ を 用いて，つぎの和と差を計算する。

$$
\begin{aligned}
& Y_{\text {cout }}^{k}(i, j)=Y_{\text {ss }}^{k}(i, j)+Y_{c c}^{k}(i, j) \\
& Y_{\text {sout }}^{k}(i, j)=Y_{\text {sc }}^{k}(i, j)-Y_{c s}^{k}(i, j)
\end{aligned}
$$$$
\text { ここで, } Y_{\text {cout }}^{k}(i, j) \text { は } Y_{\text {out }}^{+}(i, j, t) \text { に, } Y_{\text {sout }}^{k}(i, j) \text { は }
$$$$
Y_{\text {out }}^{-}(i, j, t) \text { に，それぞれ対応している。 }
$$

step4 $k$ を $k+1$ として step1にもどり, 以下繰り返す。 step3 で得られた $Y_{\text {cout }}^{k}(i, j)$ は, Fig.3 と同じ波になる。つ ぎに (16) 式，(17) 式は解析 1 における信号の分解と再構 成を示した文献 (5) での分解波と一致することを示す。

〈4・4〉 解析 1 における信号の分解と再構成の問題へ の帰着 (18) 式の $G_{+}(i, j), G_{-}(i, j), H_{+}(i, j)$ および 
$H_{-}(i, j)$ は一見すると複雑に見えるが， $\omega_{i j}^{-}=\omega_{i}-\lambda_{j}$, $\omega_{i j}^{+}=\omega_{i}+\lambda_{j}$ および $q_{j}$ は周波数 $\lambda_{j}$ の $T$ 周期分の長 さであるから $\lambda_{j} q_{j} / 2=T \pi$ となり, $\sin \left(\lambda_{j} q_{j} / 2\right)=0$, $\cos \left(\lambda_{j} q_{j} / 2\right)= \pm 1$ の関係が成り立つことから，これらの 関係を用いて簡潔に表すことができる。はじめに $G_{+}(i, j)$ の展開を示す。

$$
\begin{aligned}
G_{+}(i, j)= & \frac{2 f_{j}}{T}\left\{\frac{1}{\omega_{i j}^{-}} \sin \left(\frac{\omega_{i j}^{-}}{2} q_{j}\right) \cos \left(\frac{\omega_{i j}^{-}}{2} q_{j}\right)\right. \\
& \left.+\frac{1}{\omega_{i j}^{+}} \sin \left(\frac{\omega_{i j}^{+}}{2} q_{j}\right) \cos \left(\frac{\omega_{i j}^{+}}{2} q_{j}\right)\right\} \\
= & \frac{2 f_{j}}{T} \frac{1}{\omega_{i}-\lambda_{j}}\left\{\left(\sin \left(\frac{\omega_{i}}{2} q_{j}\right) \cos \left(\frac{\lambda_{j}}{2} q_{j}\right)\right.\right. \\
& \left.-\cos \left(\frac{\omega_{i}}{2} q_{j}\right) \sin \left(\frac{\lambda_{j}}{2} q_{j}\right)\right) \\
& \left.\times\left(\cos \left(\frac{\omega_{i}}{2} q_{j}\right) \cos \left(\frac{\lambda_{j}}{2} q_{j}\right)+\sin \left(\frac{\omega_{i}}{2} q_{j}\right) \sin \left(\frac{\lambda_{j}}{2} q_{j}\right)\right)\right\} \\
& +\frac{2 f_{j}}{T} \frac{1}{\omega_{i}+\lambda_{j}}\left\{\left(\sin \left(\frac{\omega_{i}}{2} q_{j}\right) \cos \left(\frac{\lambda_{j}}{2} q_{j}\right)\right.\right. \\
& \left.+\cos \left(\frac{\omega_{i}}{2} q_{j}\right) \sin \left(\frac{\lambda_{j}}{2} q_{j}\right)\right) \\
& \left.\times\left(\cos \left(\frac{\omega_{i}}{2} q_{j}\right) \cos \left(\frac{\lambda_{j}}{2} q_{j}\right)-\sin \left(\frac{\omega_{i}}{2} q_{j}\right) \sin \left(\frac{\lambda_{j}}{2} q_{j}\right)\right)\right\} \\
= & \frac{2 f_{j}}{T} \frac{\omega_{i}}{\omega_{i}^{2}-\lambda_{j}^{2}} \sin \left(\omega_{i} q_{j}\right) \ldots \ldots \ldots \ldots \ldots \ldots
\end{aligned}
$$

同様に， $G_{-}(i, j), H_{+}(i, j)$ および $H_{-}(i, j)$ は，つぎのよ うに表される。

$$
\begin{aligned}
& G_{-}(i, j)=\frac{2 f_{j}}{T} \frac{\lambda_{j}}{\omega_{i}^{2}-\lambda_{j}^{2}} \sin \left(\omega q_{j}\right) \\
& H_{+}(i, j)=\frac{2 f_{j}}{T} \frac{\omega_{i}}{\omega_{i}^{2}-\lambda_{j}^{2}}\left(1-\cos \left(\omega_{i} q_{j}\right)\right) \\
& H_{-}(i, j)=\frac{2 f_{j}}{T} \frac{-\lambda_{j}}{\omega_{i}^{2}-\lambda_{j}^{2}}\left(1-\cos \left(\omega_{i} q_{j}\right)\right) \cdots
\end{aligned}
$$

文献 (5) において，解析 1 に基づいた分解波は，つぎのよ うに表された。

$$
\begin{aligned}
\tilde{Y}_{c}(i, j, t)=A_{i}( & I_{c c}(i, j) \sin \left(\omega_{i} t+\phi_{i}\right) \\
& \left.-I_{s c}(i, j) \cos \left(\omega_{i} t+\phi_{i}\right)\right) \\
\tilde{Y}_{s}(i, j, t)=A_{i}( & -I_{s s}(i, j) \cos \left(\omega_{i} t+\phi_{i}\right)+ \\
& \left.+I_{c s}(i, j) \sin \left(\omega_{i} t+\phi_{i}\right)\right) \cdots
\end{aligned}
$$

ここで, $I_{c c}(i, j), I_{s s}(i, j), I_{s c}(i, j)$ および $I_{c s}(i, j)$ は

$$
\begin{aligned}
& I_{c c}(i, j)=\frac{2 f_{j}}{T} \frac{\omega_{i}}{\omega_{i}^{2}-\lambda_{j}^{2}} \sin \left(\omega_{i} q_{j}\right) \\
& I_{s s}(i, j)=\frac{2 f_{j}}{T} \frac{\lambda_{j}}{\omega_{i}^{2}-\lambda_{j}^{2}} \sin \left(\omega_{i} q_{j}\right) \\
& I_{s c}(i, j)=\frac{2 f_{j}}{T} \frac{\omega_{i}}{\omega_{i}^{2}-\lambda_{j}^{2}}\left(1-\cos \left(\omega_{i} q_{j}\right)\right) \\
& I_{c s}(i, j)=\frac{2 f_{j}}{T} \frac{-\lambda_{i}}{\omega_{i}^{2}-\lambda_{j}^{2}}\left(1-\cos \left(\omega_{i} q_{j}\right)\right)
\end{aligned}
$$

である。(22) 式，(23) 式と (25) 式は同じである。したがっ て, $Y_{\text {out }}^{+}(i, j, t)=\tilde{Y}_{c}(i, j, t), Y_{\text {out }}^{-}(i, j, t)=\tilde{Y}_{s}(i, j, t)$ であ り, $Y_{\text {out }}^{+}(i, j, t), Y_{\text {out }}^{-}(i, j, t)$ は解析 1 における分解波と同 じになる。したがって, 解析 2 における信号の分解と再構 成は解析 1 における信号の分解と再構成の問題に帰着する。 つぎに解析 2 を用いたときの信号の再構成について示す。

\section{5. 信号の再構成}

3 章で信号の検出範囲 $B$ と切出し波の長さ $T / f_{j}$ で作ら れる面積は一定の $2\left(=B T / f_{j}\right)$ であることを示した。 $T$ を一定にすると $B / f_{j}$ も一定になる。いま, 聴覚細胞の設 定周波数を等比数列的に増加させていくと， $f_{j}$ によらず $B$ 内には同じ数の聴覚細胞が存在することになる。基本波, 高調波などで構成されている母音のような場合は，基本波 や高調波に応じた所で大きな分解波が現れ，それらの大き く表われている部分で, それぞれ分解波の数が同じになる ようにしてとり出すと, $f_{j}$ によらず $B$ 内には同じ数の聴 覚細胞が存在するのであるから，基本波に対応した部分で 取り出した分解波も高調波に対応した部分で取り出した分 解波も同じ程度に取り出したことになる。それぞれの部分 で取り出した分解波を加えると信号を構成している波が近 似的に得られ，これにより信号波形の詳細な分析ができる。 つぎに分解波を全て加えて再構成波を得ることについて示 す。(19) 式の分解波は各聴覚細胞の出力であり，(19) 式を 各聴覚細胞について加えたのが再構成波である。ここでは $Y_{\text {out }}^{+}(i, j, t)$ を各聴覚細胞について加えた再構成波 $\bar{Y}_{\text {out }}(i, t)$ について示す。

$$
\begin{aligned}
\bar{Y}_{\text {out }}(i, t)= & \sum_{j=1}^{n} Y_{\text {out }}^{+}(i, j, t) \\
= & A_{i} \sum_{j=1}^{n}\left\{G_{+}(i, j)\right\} \sin \left(\omega_{i} t+\phi_{i}\right) \\
& \left.-A_{i} \sum_{j=1}^{n}\left\{H_{+}(i, j)\right\} \cos \left(\omega_{i} t+\phi_{i}\right)\right)
\end{aligned}
$$

ここで

$$
\begin{aligned}
& Z_{G}(i)=\sum_{j=1}^{n} G_{+}(i, j) \quad Z_{H}(i)=-\sum_{j=1}^{n} H_{+}(i, j) \\
& \bar{r}(i)=\sqrt{Z_{G}^{2}(i)+Z_{H}^{2}(i)} \\
& \bar{g}(i)=\tan ^{-1}\left(Z_{H}(i) / Z_{G}(i)\right) \ldots \ldots \ldots \ldots \ldots
\end{aligned}
$$

とおくと, (26) 式は

$$
\bar{Y}_{\text {out }}(i, t)=A_{i} \bar{r}(i) \sin \left(\omega_{i} t+\phi_{i}+\bar{g}(i)\right)
$$

となる。(28) 式は周波数が信号の周波数 $\omega_{i}$ で, 振幅が $\bar{r}(i)$ 倍となり, さらに新しく位相 $\bar{g}(i)$ が生じることを表してい る。 $\bar{r}(i)$ が振幅特性であり, $\bar{g}(i)$ が位相特性である。分解 波を加え合わせると元の信号波形が再構成されるが，この 


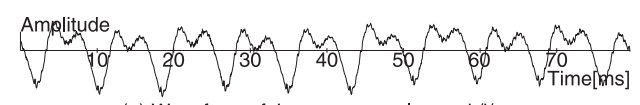

(a) Waveform of Japanese vocal sound /i/

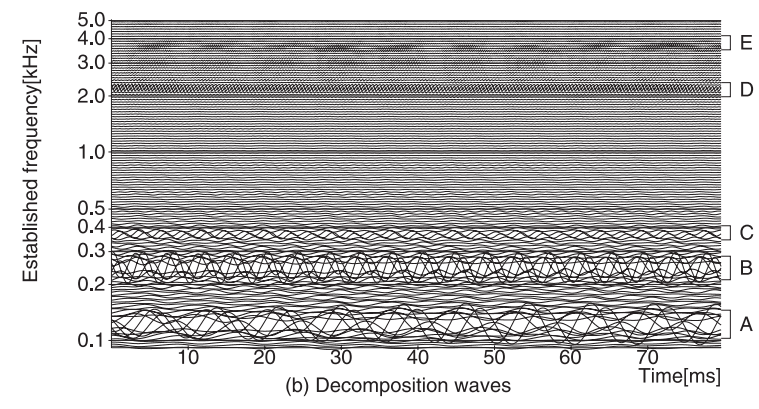

Fig. 4. The waveform of Japanese vocal sound /i/ and the decomposition waves

再構成は保証されたものではない。元の信号を再構成する ためには，つぎの条件

(1) 周波数によらず振幅特性（ゲイン）が一定

(2) 位相特性が直線位相特性

を満たすことである。条件 (2) はデジタルフィルタの設計に おいて歪のない波形を得るための条件として知られている。

\section{6. 実信号の解析例}

ここでは，日本語の音声/i/を用いた実際の解析例を示す。 音声データはサンプリング周波数 $44.1 \mathrm{kHz}, 16$ ビットモノ ラルで取得した。聴覚細胞については周期数 $T$ を 16 とし, 設定周波数を $10 \mathrm{~Hz}$ から約 $1.5 \%$ づつ増加させて約 $23 \mathrm{kHz}$ までの 520 個の聴覚細胞を設定した。2 章で示したように 設定周波数が高くなると $T$ 周期内に存在するデー夕数が少 なくなるため, 設定周波数を約 $1.5 \%$ づつ増加させること が困難になる。そこで，自然スプライン補間を行ってサン プリング周波数を 10 倍の $441 \mathrm{kHz}$ とし，聴覚細胞の設定周 波数が $500 \mathrm{~Hz}$ まではサンプリング周波数を $44.1 \mathrm{kHz}$ とし， $500 \mathrm{~Hz}$ 以上ではサンプリング補間した $441 \mathrm{kHz}$ のデータを 用いて聴覚細胞を設定した。音声 $/ \mathrm{i} /$ の波形と,〈4・3節で 示した分解波を得るための処理手順（step1 から step4）で 得られた $Y_{\text {cout }}^{k}(i, j)$ を Fig.4 に示す。Fig.4(a) は音声/i/の 波形である。Fig.4(b) は分解波で，横軸は時間，左の縦軸 は周波数である。分解波は $10 \mathrm{~Hz}$ から約 $23 \mathrm{kHz}$ まであるが, ここでは約 $100 \mathrm{~Hz}$ から $5 \mathrm{kHz}$ までを示した。右側の A か ら E は大きく分解波が現れている部分である。この A から E を取り出した分解波を Fig.5 に示す。Fig.5 の A から E で，それぞれ分解波を加えた波等を Fig.6 に示す。Fig.6(a) は音声 $/ \mathrm{i} /$ の波形である。Fig.6(h) は基本波であり，その周 波数は $113 \mathrm{~Hz}$ である。Fig.6(g) は第 2 高調波で，周波数は 基本周波数の 2 倍で $227 \mathrm{~Hz}$ である。Fig.6(f) は第 3 高調波 で，周波数は 3 倍の $340 \mathrm{~Hz}$ である。Fig.6(e) と Fig.6(d) はそれぞれ $2 \mathrm{kHz}$ 強と約 $4 \mathrm{kHz}$ に現れているノイズのよう な高い周波数の波である。Fig.6(b) は基本波から，この高 い周波数の波までを加えた波であり，Fig.6(a) の音声波形 を高い精度で近似している。この波形で wave ファイルを
E
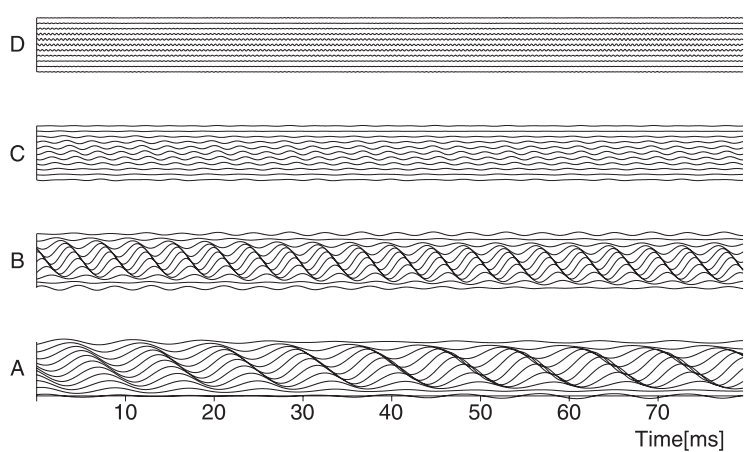

Fig. 5. The decomposition waves at A, B, C, D and $\mathrm{E}$

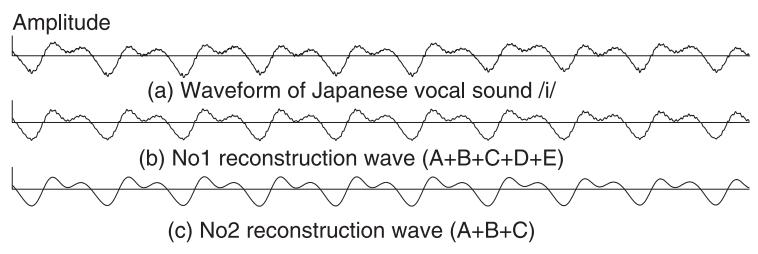

d) No2 high frequency wave

(e) No1 high frequency wave

(f) No3 harmonic wave $(340 \mathrm{~Hz})$

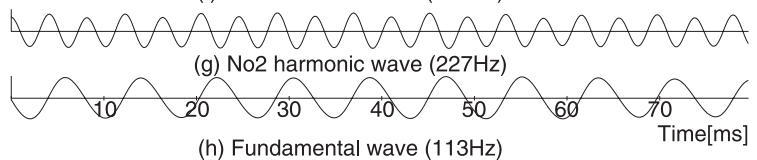

Fig. 6. The waveform of Japanese vocal sound /i/ and the waves which constitute vocal sound /i/ and the reconstruction waves

作成し, 再生して聞いてみると, Fig.6(a)の場合と同じ声 色で「イ」と聞こえる。Fig.6(c) は基本波と高調波を加え た波であり, Fig.6(b) の波形と殆ど同じである。ただノイ ズのような高い周波数の波が無いことだけが異なっている。 Fig.6(c) の波形を同様に再生して聞いてみると「ウ」と聞 こえる。「イ」と「ウ」のパターンの違いはノイズのような 高周波の波の存在であることが分かる。このように信号の 詳細な分析ができる。

つぎに，全ての分解波を加えて信号波形を再構成するこ とを示す。信号波形を再構成するための条件は，5章で示し た条件 (1)，(2) が成立することであり，この特性を Fig.7 に示す。Fig.7(a) は振幅特性で, ゲインは周波数によらず, ほぼ一定であって条件 (1) を満たしていることが分かる。 Fig.7(b) は位相特性で, ほぼ直線位相特性になっていて, 条 件 (2) を満たしていることが分かる。全ての分解波を加えた 再構成波を Fig.8 に示す。Fig.8(a) は音声波形で Fig.8(b) は再構成波である。Fig.8(b) は Fig.7 の特性を反映して, 高い精度で元の波形を再構成していることが分かる。 


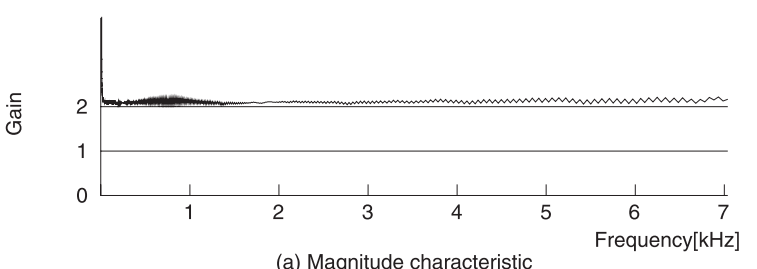

(a) Magnitude characteristic

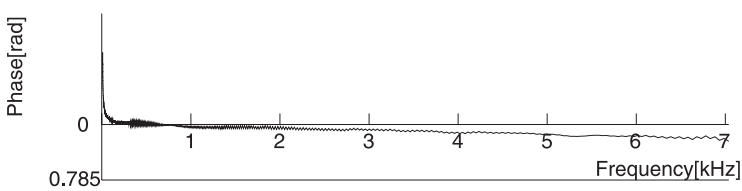

(b) Phase characteristic

Fig. 7. Magnitude characteristic and phase characteristic

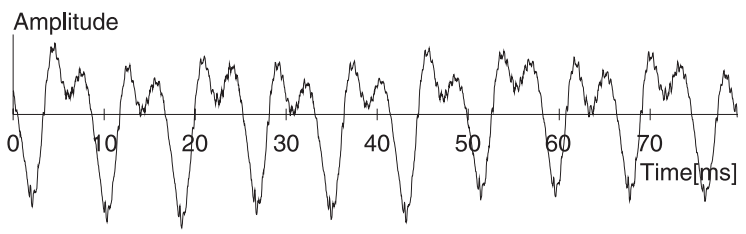

(a) Signal

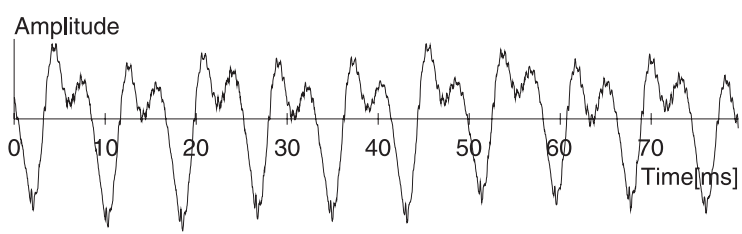

(b) Reconstruction wave

Fig. 8. The waveform of Japanese vocal sound /i/ and the reconstruction wave

\section{7. おわりに}

本論文で扱っている解析 2 では，(6) 式の内積は分解波 にはならない。そこで，4.3節で示した step1 から step4の 処理を施すことによって得られた波が，解析 1 における分 解波と一致することを示した。解析 2 における分解波が解 析 1 における分解波と同じになることから，再構成につい ても解析 1 の場合と同じになる。よって, 解析 2 における 信号の分解と再構成は，解析 1 における信号の分解と再構 成の問題に帰着することを示した。数值解析例では日本語 の音声 $/ \mathrm{i} /$ を用いて，基本波，高調波および高周波数の波に 分解して表し，これらの全ての波を加えた波および基本波 と高調波だけを加えた波で wave ファイルを作成し, 再生 して聞いてみることで，音声/i/と/u/のパターンの違いを
明確にした。このような詳細な分析は，広い分野で適用で きるものと思われる。全ての分解波を加えた再構成波では, 振幅特性および位相特性が元の信号を再構成するための条 件をほぼ満たしており，これを反映して，音声波形を高い 精度で近似した再構成波が得られることを示した。

(平成 19 年 10 月 23 日受付，平成 20 年 3 月 26 日再受付)

$$
\text { 文献 }
$$

(1) N. Murata: "Independent Component Analysis", p.190,Tokyo Denki University Press (2005) (in Japanese) 村田 昇:「独立成分分析」, p.190, 東京電機大学出版局 (2005)

(2) C. M. Harris and W. M. Waite: "Response of spectrum analyzers of the bank-of-filters type to signal generated by vowel sound", J.A.S.A, 18, 1, pp.1972-1977 (1963)

(3) A. Grossmann and J. Morlet: "Decomposition of Hardy function into square integrable wavelets of constant shape", SIAM J. Math. Anal. 15, pp.723-736 (1984)

(4) H. Nakatsuji and S. Omatu: "Real Time Spectral Analysis", IEEJ Trans. EIS, Vol.126, No.3, pp.383-388 (2006) (in Japanese)

中辻秀人 · 大松 繁: 「リアルタイムスペクトル解析」, 電学論 $\mathrm{C}$, 126, 3, pp.383-388 (2006)

(5) H. Nakatsuji and S. Omatu: "Decomposition and Reconstruction of Signal in Real-Time Spectral Analysis", IEEJ Trans. EIS, Vol.127, No.7, pp.1123-1130 (2007) (in Japanese) 中过秀人・大松 繁:「リアルタイムスペクトル解析における信号の 分解と再構成」, 電学論 C, 127, 7, pp.1123-1130 (2007)

中 辻 秀 人 (正員) 1947 年生。1970 年 3 月大阪府立大学

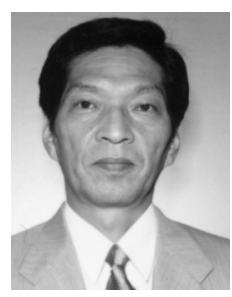
工学部機械工学科卒業。同年, 航空自衛隊入隊。 1978 年 3 月防衛大学校理工学研究科修了。戦闘 機パイロット，テストパイロット，技術幹部等と して勤務。この間，国産機の開発，試験等に従事。 2002 年 10 月定年退官。 2004 年 4 月より, 大阪 府立大学工学部研究生。計測自動制御学会, シス テム制御情報学会会員。

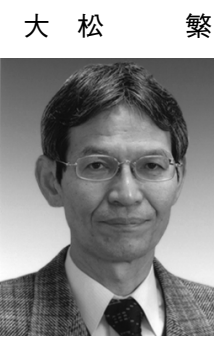

（正員） 1974 年大阪府立大学大学院博士課程修 了。同年, 徳島大学工学部情報工学科助手。1988 年同知能情報工学科教授。1995 年大阪府立大学工 学部情報工学科教授となり, 現在に至る。工学博 士。ニューラルネットワークの研究に従事。1991 年電気学会学術振興賞·論文賞, 1995 年計測自 動制御学会論文賞, 1996 年市村賞, 2005 年電気 学会業績賞受賞, IEEE Trans. on Neural Network の Associate Editor. システム制御情報学会, 計測自動制御学 会, SIAM, IEEE 会員。 